University of Nebraska - Lincoln

DigitalCommons@University of Nebraska - Lincoln

Biological Systems Engineering: Papers and

Publications

Biological Systems Engineering

6-1994

\title{
Hydraulic Conditions Required to Move Unanchored Residue Materials
}

John E. Gilley

University of Nebraska-Lincoln, john.gilley@ars.usda.gov

E. R. Kottwitz

University of Nebraska-Lincoln

G. A. Wieman

University of Nebraska-Lincoln

Follow this and additional works at: https://digitalcommons.unl.edu/biosysengfacpub

Part of the Biological Engineering Commons

Gilley, John E.; Kottwitz, E. R.; and Wieman, G. A., "Hydraulic Conditions Required to Move Unanchored Residue Materials" (1994). Biological Systems Engineering: Papers and Publications. 72. https://digitalcommons.unl.edu/biosysengfacpub/72

This Article is brought to you for free and open access by the Biological Systems Engineering at DigitalCommons@University of Nebraska - Lincoln. It has been accepted for inclusion in Biological Systems Engineering: Papers and Publications by an authorized administrator of DigitalCommons@University of Nebraska Lincoln. 


\title{
Hydraulic Conditions Required to Move UNANCHORED Residue MATERIALS
}

\author{
By J. E. Gilley, ${ }^{1}$ E. R. Kottwitz, ${ }^{2}$ and G. A. Wieman ${ }^{3}$
}

\begin{abstract}
Hydraulic conditions required to initiate movement of unanchored residue materials are identified in the present study. Selected amounts of corn, cotton, pine needles, sorghum, soybean, sunflower, and wheat residue are placed in a flume on a sand surface, and flow is then introduced at the top of the flume in progressive increments. The discharge rate and flow velocity necessary to cause residue movement are determined. The ratio of critical flow depth to residue diameter, critical Reynolds number, critical shear stress, dimensionless shear stress, and boundary Reynolds number are calculated from hydraulic measurements. Regression equations are developed to relate dimensionless shear stress to boundary Reynolds number and residue diameter. Boundary Reynolds number, in turn, is related to residue diameter and cover. Close agreement is found between predicted and actual parameter values obtained from the regression relations. The regression equations can be used to estimate the beginning of motion for other residue materials if residue diameter and cover are known.
\end{abstract}

\section{INTRODUCTION}

Soil erosion is a significant problem on some furrow-irrigated areas. Irrigation-induced erosion can result in loss of soil productivity and decreased profits for farmers who irrigate. Water quality may also be adversely affected by soil erosion resulting from irrigation (Deason 1989).

The presence of crop residue on the soil surface has been found to substantially reduce soil loss from furrows (Aarstad and Miller 1978, 1981; Brown 1985; Brown and Kemper 1987; Miller and Aarstad 1983; Miller et al. 1987). Conservation tillage systems are designed to maintain residue from the previous crop within the furrow. Equipment is also available for adding straw to irrigation furrows to reduce erosion.

Crop residues can serve to prevent rill development within furrows. However, if critical shear stress of the residue material is exceeded and crop residue is removed by irrigation flow, rill formation may begin. Once rills have become established within furrows, soil loss usually increases substantially.

Critical slope lengths for unanchored cornstalk and wheat-straw residue were identified in a rainfall-simulation study conducted by Foster et al. (1982a). Foster et al. (1982b) also analyzed the hydraulics of mulch failure. Equations were derived that gave critical discharge rate and critical slope length at which the mulch began to move.

The effects of surface roughness on the beginning of motion for selected unanchored residue materials were determined by Gilley and Kottwitz (1992). Regression equations were identified that related dimensionless shear stress

\footnotetext{
'Agric. Engr., USDA-ARS, Univ. of Nebraska, Lincoln, NE 68583-0934. $\mathrm{NE}$.

${ }^{2}$ Res. Engr., Dept. of Biological Systems Engrg., Univ. of Nebraska, Lincoln, NE.

${ }^{3}$ Res. Engr., Dept. of Biological Systems Engrg., Univ. of Nebraska, Lincoln,

Note. Discussion open until November 1, 1994. To extend the closing date one month, a written request must be filed with the ASCE Manager of Journals. The manuscript for this paper was submitted for review and possible publication on June 9, 1993. This paper is part of the Journal of Irrigation and Drainage Engineering, Vol. 120, No. 3, May/June, 1994. CASCE, ISSN 0733-9437/94/0003-0591/\$2.00 + $\$ .25$ per page. Paper No. 6275 .
} 
to boundary Reynolds number on both smooth and sand surfaces. Data used to derive the regression equations were obtained on surfaces with relatively small amounts of crop residue.

The objective of the present study was to identify the hydraulic conditions required to move varying quantities of unanchored residue materials. In the experimental portion of this investigation, several types and rates of crop residue were examined. The residue materials were placed in a flume on a sand surface, and the discharge rate and flow velocity required to initiate residue movement were identified. The experimental data were then used to develop equations for estimating the beginning of motion for other residue materials.

\section{HYDRAULIC EQUATIONS}

The continuity equation for steady flow is defined as

$$
Q=V A
$$

where $Q=$ flow rate; $V=$ mean flow velocity; and $A=$ cross-sectional flow area. For a rectangular flume, flow depth $y$ is given as

$$
y=\frac{Q}{V b}
$$

where $b=$ flow width. In the present study, flow depth was determined indirectly using (2) and measurements of $Q, V$, and $b$.

Reynolds number $R$, which is used to describe the ratio of inertial forces to viscous forces, can be expressed as

$$
\mathrm{R}=\frac{V R}{v}
$$

where $v=$ kinematic viscosity; and $R=$ hydraulic radius. Kinematic viscosity can be determined directly from water temperature. The Reynolds number value that causes unanchored residue materials to begin to move is defined as the critical Reynolds number.

Hydraulic radius $R$ is given as

$$
R=\frac{A}{P}
$$

where $P=$ wetted perimeter. For a rectangular flume of width $b$

$$
R=\frac{b y}{b+2 y}
$$

For overland flow conditions where flow width is much greater than flow depth, hydraulic radius can be assumed to be approximately equal to flow depth. For broad sheet flow

$$
\mathrm{R} \cong \frac{q}{v} \cong \frac{V y}{v}
$$

where flow rate per unit width $q$ is given as

$$
q=\frac{Q}{b}
$$


Water flowing over a surface exerts a force on the surface that acts in the direction of flow. This force per unit wetted area is called shear stress $\tau$ and is expressed as

$$
\tau=\gamma R S
$$

where $\gamma=$ specific weight of water; and $S=$ average slope. In the present study, critical shear stress $\tau_{c}$ is defined as the force per unit wetted area required to initiate movement of unanchored residue material.

Shear velocity $V^{*}$ is given as

$$
V^{*}=(g R S)^{1 / 2}
$$

where $g=$ gravitational acceleration. Shear velocity at the threshold condition for residue movement is defined as critical shear velocity $V_{c}^{*}$.

The beginning of motion for unanchored residue materials can be identified using dimensionless shear stress $F^{*}$, which is defined as

$$
F^{*}=\frac{\tau_{c}}{\left(\gamma-\gamma_{s}\right) D}
$$

where $\gamma_{s}=$ specific weight of residue material; and $D=$ residue diameter. The beginning of motion for unanchored residue materials is also a function of boundary Reynolds number $R^{*}$, which is expressed as

$$
\mathrm{R}^{*}=\frac{V_{c}^{*} D}{v}
$$

Boundary Reynolds number is a dimensionless parameter.

To determine the dimensionless shear stress and the boundary Reynolds number, the hydraulic radius must first be identified. If roughness-coefficient values are known, hydraulic radius can be calculated using the Chezy, Darcy-Weisbach, or Manning equations. The effects of random roughness of the soil surface on hydraulic roughness coefficients were examined by Gilley and Finkner (1991). Hydraulic roughness coefficients for selected residue materials were reported by Gilley et al. (1991). Equations for estimating roughness coefficients for rills, and gravel and cobble surfaces were identified by Gilley et al. $(1990,1992)$. For most conditions, raindrop impact has been found to have a minimal effect on hydraulic resistance (Shen and Li 1973).

\section{EXPERIMENTAL PROCEDURES}

Corn, cotton, pine needles, sorghum, soybean, sunflower, and wheat residue were used in the present investigation. Needles produced by ponderosa pine were included to allow evaluation of conditions existing for materials with very small diameters. For each type of residue, 10 randomly selected residue elements were used for characterizing residue dimensions. Mean residue diameter and length, and the standard deviation among measurements are shown in Table 1.

The type or manufacturer of harvesting equipment would be expected to influence residue length. Residue materials are typically subjected to weathering and decomposition following harvest. With the exception of cotton, the vegetative materials used in the present study had all undergone weathering over the winter. Cotton residue was obtained soon after harvest. No attempt was made to segregate or trim individual residue elements. 
TABLE 1. Diameter, Length, and Density of Selected Residue Materials

\begin{tabular}{l|c|c|c}
\hline \hline $\begin{array}{c}\text { Residue type } \\
(1)\end{array}$ & $\begin{array}{c}\text { Diameter } \\
(\mathrm{cm}) \\
(2)\end{array}$ & $\begin{array}{c}\text { Length }^{\mathrm{a}} \\
(\mathrm{cm}) \\
(3)\end{array}$ & $\begin{array}{c}\text { Density } \\
\left(\mathrm{kg} / \mathrm{m}^{3}\right) \\
(4)\end{array}$ \\
\hline Corn & $2.38(0.62)$ & $40.3(9.92)$ & 168 \\
Cotton & $0.77(0.18)$ & $21.7(5.22)$ & 495 \\
Pine needles & $0.11(0.02)$ & $9.27(1.64)$ & 437 \\
Sorghum & $1.81(0.17)$ & $48.4(4.77)$ & 161 \\
Soybeans & $0.60(0.11)$ & $33.5(11.10)$ & 258 \\
Sunflower & $2.47(0.40)$ & $45.0(3.12)$ & 99 \\
Wheat & $0.29(0.13)$ & $15.2(4.71)$ & 148 \\
\hline
\end{tabular}

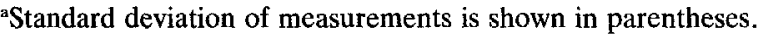

Density of the residue materials is also presented in Table 1 . To determine density, the residue material was first placed in an oven and dried. The residue material was then removed from the oven, and its mass was measured. To prevent absorption during the experiment, the residue material was then submerged in water. The volume of residue was identified by placing it in a container of known volume and measuring the quantity of water required to fill the container. Residue mass and volume were then used to calculate density.

The surface covers and residue rates at which the materials were applied are shown in Table 2 . The unanchored residue materials were placed randomly on a surface containing sand particles that varied in diameter from $1 \mathrm{~mm}$ to $2 \mathrm{~mm}$. For each of the residue materials except cotton, five residue rates were selected. The amount of cotton residue available for testing was limited and, therefore, only three cotton-residue treatments were used. It should be noted that residue materials with relatively small diameters such as pine needles and wheat provide greater surface cover at a given residue rate.

Surface cover may vary substantially between upland sites. Significant differences in residue cover may occur during the year at a particular location. The broad range of surface-cover values used in the present investigation represent the spatial and seasonal variability characteristic of upland cropping conditions.

A photographic grid procedure (Laflen et al. 1978) was used before each test to measure the percentage of surface cover provided at a given residue rate. Residue cover was photographed using $35-\mathrm{mm}$ color slide film. The slides were projected onto a screen on which a grid had been superimposed. The number of grid intersections over residue material were determined visually from the projected slides and surface cover was then calculated.

Tests were conducted using a $0.91-\mathrm{m}$-wide, $7.31-\mathrm{m}$-long and $0.279-\mathrm{m}$-deep flume. A constant head tank was used to supply water to the flume. The slope of the flume was maintained at $1.35 \%$. Critical shear-stress values for other slopes can be estimated since (8) uses slope as an independent variable.

Critical flow rate was determined visually. Flow was introduced in progressive increments until approximately $50 \%$ of the unanchored residue material was dislodged. Three replicated tests were run for each residue material to determine critical flow rate. After completion of each replicated test, the unanchored residue material was repositioned. Water temperature was maintained at approximately $21^{\circ} \mathrm{C}$ throughout the study. 
TABLE 2. Physical Characteristics of Selected Residue Materials

\begin{tabular}{|c|c|c|c|c|c|}
\hline $\begin{array}{l}\text { Residue type } \\
\text { (1) }\end{array}$ & $\begin{array}{l}\text { Surface } \\
\text { cover } \\
(\%) \\
(2)\end{array}$ & $\begin{array}{l}\text { Residue } \\
\text { rate } \\
\text { (t/ha) } \\
\text { (3) }\end{array}$ & $\begin{array}{l}\text { Residue } \\
\text { spacing } \\
\text { (cm) } \\
\text { (4) }\end{array}$ & $\begin{array}{l}\text { Ratio of residue } \\
\text { spacing to } \\
\text { residue diameter } \\
\text { (5) }\end{array}$ & $\begin{array}{l}\text { Ratio of critical } \\
\text { flow depth to } \\
\text { residue diameter } \\
\text { (6) }\end{array}$ \\
\hline Corn & 5 & 0.68 & 47.6 & 20.0 & 0.37 \\
\hline Corn & 13 & 2.30 & 18.3 & 7.7 & 0.44 \\
\hline Corn & 29 & 4.47 & 8.2 & 3.4 & 0.56 \\
\hline Corn & 61 & 7.77 & 3.9 & 1.6 & 0.62 \\
\hline Corn & 84 & 14.86 & 2.8 & 1.2 & 0.60 \\
\hline Cotton & 5 & 1.56 & 15.4 & 20.0 & 1.21 \\
\hline Cotton & 28 & 5.28 & 2.8 & 3.6 & 1.56 \\
\hline Cotton & 53 & 10.25 & 1.5 & 1.9 & 2.02 \\
\hline Pine needles & 12 & 0.28 & 0.9 & 8.3 & 3.21 \\
\hline Pine needles & 30 & 0.96 & 0.4 & 3.3 & 7.19 \\
\hline Pine needles & 46 & 1.87 & 0.2 & 2.2 & 10.92 \\
\hline Pine needles & 74 & 3.25 & 0.1 & 1.4 & 14.55 \\
\hline Pine needles & 93 & 6.22 & 0.1 & 1.1 & 21.74 \\
\hline Sorghum & 7 & 0.57 & 25.0 & 14.3 & 0.36 \\
\hline Sorghum & 19 & 1.94 & 9.5 & 5.3 & 0.52 \\
\hline Sorghum & 32 & 3.77 & 5.7 & 3.1 & 0.52 \\
\hline Sorghum & 54 & 6.54 & 3.4 & 1.9 & 0.59 \\
\hline Sorghum & 81 & 12.51 & 2.2 & 1.2 & 0.57 \\
\hline Soybeans & 7 & 0.44 & 8.6 & 14.3 & 1.51 \\
\hline Soybeans & 27 & 1.47 & 2.2 & 3.7 & 2.25 \\
\hline Soybeans & 41 & 2.85 & 1.5 & 2.4 & 3.29 \\
\hline Soybeans & 68 & 4.95 & 0.9 & 1.5 & 4.45 \\
\hline Soybeans & 85 & 9.48 & 0.7 & 1.2 & 6.73 \\
\hline Sunflower & 8 & 1.03 & 30.9 & 12.5 & 0.37 \\
\hline Sunflower & 24 & 3.50 & 10.3 & 4.2 & 0.51 \\
\hline Sunflower & 51 & 6.80 & 4.8 & 2.0 & 0.52 \\
\hline Sunflower & 73 & 11.80 & 3.4 & 1.4 & 0.57 \\
\hline Sunflower & 98 & 22.57 & 2.5 & 1.0 & 0.64 \\
\hline Wheat & 8 & 0.10 & 3.6 & 12.5 & 1.40 \\
\hline Wheat & 26 & 0.32 & 1.1 & 3.8 & 2.20 \\
\hline Wheat & 44 & 0.63 & 0.7 & 2.3 & 4.03 \\
\hline Wheat & 64 & 1.09 & 0.5 & 1.6 & 5.32 \\
\hline Wheat & 91 & 2.09 & 0.3 & 1.1 & 7.49 \\
\hline
\end{tabular}

Once critical flow rate was identified, line sources of fluorescent dye were injected across the flume at downslope distances of $0.91 \mathrm{~m}$ and $4.57 \mathrm{~m}$. Travel time of the dye-concentration peaks was determined using a fluorometer. Mean flow velocity was identified by dividing the distance between the two line sources of dye $(3.66 \mathrm{~m})$ by the difference in travel time between the two dye-concentration peaks. Three measurements of flow velocity were made for each critical flow rate.

\section{FLOW MECHANICS}

When developing theoretical flow concepts, Chow (1959) identified three basic types of flow over rough surfaces. Isolated-roughness flow exists when the roughness elements are so far apart that the wake and vortex at each 
element are completely developed and dissipated before the flow reaches the next element. When the roughness elements are placed closer together, such that the wake and vortex at each element interferes with those developed at the following element, wake-interference flow results. Finally, quasismooth flow occurs when the roughness elements are so close together that the flow essentially skims the crest of the roughness elements.

Information on residue spacing and the ratio of residue spacing to residue diameter could provide insight into the flow processes affecting residue movement. Since the residue materials were placed randomly, surface-cover data can be used to identify the amount of residue present at a representative cross section. As an example, a $25 \%$ surface cover of corn would provide $0.25 \mathrm{~m}$ of residue along a representative $1-\mathrm{m}$ cross section. Since mean diameter for corn residue is $2.38 \mathrm{~cm}$, approximately 11 residue elements would be present. Average spacing of roughness elements would be approximately $9.5 \mathrm{~cm}$ for the representative $1-\mathrm{m}$ cross section. This would represent a distance of approximately four times the roughness height.

Table 2 presents ratios of residue spacing to residue diameter. This information suggests that isolated-roughness flow is the predominant flow condition at the lower residue rates. Wake-interference flow would be expected to occur for the intermediate residue rates. For the higher residue rates, quasi-smooth flow would dominate.

The submerged weight of the residue material, a lift force and a drag force may all influence the movement of unanchored residue. Both lift and drag forces depend upon the same variables, and constants found in theoretical equations used to solve for these variables are usually determined empirically. Thus, standard procedures used to identify incipient motion usually incorporate both lift and drag forces in the analyses. The analytical procedures used in the present investigation are similar to those of Shields (Simons and Senturk 1976). However, residue diameter has been used in place of characteristic particle diameter.

\section{RESULTS AND DISCUSSION}

Values are provided for the ratio of critical flow depth to residue diameter, critical Reynolds number, critical shear stress, dimensionless shear stress and boundary Reynolds number. Regression equations are presented for estimating dimensionless shear stress and boundary Reynolds number for selected unanchored residue materials. Limitations in the use of the regression equations are also outlined.

\section{Ratio of Critical Flow Depth to Residue Diameter}

For each of the residue materials, the ratio of critical flow depth to residue diameter usually increased with greater residue rate. A critical flow depth to residue diameter ratio less than one indicates that the diameter of the residue material is greater than critical flow depth. Table 2 shows that critical flow depth was less than the average diameter of corn, sorghum, and sunflower residue. For the larger diameter residue materials, residue movement occurred before individual residue elements became submerged. The densities of corn, sorghum, and sunflower residue (Table 1) were relatively small. Thus, a lift or buoyancy force would be expected to significantly influence incipient motion for these residue materials.

Critical flow depth was greater than the diameter of cotton, pine needles, soybean, and wheat residue (Table 2). Thus, residue movement occurred 
only after the smaller diameter residue materials had become submerged. For these residue materials, drag forces would have contributed to incipient motion.

Critical flow velocity and critical flow rate per unit width for unanchored corn and wheat residue were identified by Foster et al. (1982a). These two variables can be used to estimate critical flow depths if broad sheet flow is assumed. The ratios of critical flow depth to residue diameter indicate that the heights of the corn-residue elements were greater than critical flow depth. In contrast, the wheat-residue elements were first submerged before residue movement occurred. Similar results were found in the present investigation.

\section{Critical Reynolds Number}

Flow rates required to initiate residue movement can be estimated using critical Reynolds number values shown in Table 3. For the larger diameter residue materials (corn, sorghum, and sunflower residue), critical Reynolds number values generally decreased as the amount of residue become larger. As residue cover increases, greater hydraulic roughness coefficients and water depths result. A lift or buoyancy force is an important factor that influences incipient motion for larger diameter residue materials. Thus, as buoyancy forces increase with residue cover, smaller flow rates are required to initiate residue movement.

In contrast, drag forces are primarily responsible for moving the smaller diameter residue materials (cotton, pine needles, soybeans, and wheat). As surface cover is increased, the distance between individual residue elements is reduced, and wake-interference or quasi-smooth flow may occur (Chow 1959). Thus, greater drag forces and flow rates are necessary to initiate residue movement.

Critical Reynolds number values were determined using data from Foster et al. (1982a). For a given corn-residue rate, substantial differences in critical Reynolds number values were found between experimental sites. The cornresidue rates used by Foster et al. were within the range used in the present study. A mean critical Reynolds number value of 1,500 was found for the three sites examined by Foster et al. This number is similar to the mean value of 1,330 found for corn residue in the present investigation (Table 3).

Two of the three wheat residue rates used by Foster et al. (1982a) were comparable to those used in the present study. Data collected by Foster et al. were used to calculate critical Reynolds number values of 999 and 2,290 for wheat residue at application rates of 1.1 and $2.2 \mathrm{t} / \mathrm{ha}$, respectively. In the present investigation, critical Reynolds number values of 889 and 1,160 were found for similar residue rates.

\section{Critical Shear Stress}

Forces of static friction act between surfaces at rest with respect to each other. The smallest force necessary to initiate motion is the same as the maximum force of static friction. In the present study, critical shear stress has been defined as the force per unit area required to initiate movement of unanchored residue material.

Critical shear-stress values (Table 3) can be seen in general to increase with surface cover. As residue materials overlap at higher residue rates, increased stability can result. In addition, less flow turbulence can occur for closely spaced residue materials.

Critical shear-stress values are reported in Table 4 for locations examined by Foster et al. (1982a). On the sites where Foster et al. used corn residue, 
TABLE 3. Hydraulic Characteristics of Selected Residue Materials

\begin{tabular}{l|c|c|c|c|c}
\hline Residue type & $\begin{array}{c}\text { Surface } \\
\text { cover } \\
(1)\end{array}$ & $\begin{array}{c}\text { Critical } \\
\text { Reynolds } \\
\text { number } \\
(2)\end{array}$ & $\begin{array}{c}\text { Critical shear } \\
\text { stress } \\
(\mathrm{Pa}) \\
(4)\end{array}$ & $\begin{array}{c}\text { Dimensionless } \\
\text { shear stress } \\
\left(\times 10^{2}\right)\end{array}$ & $\begin{array}{c}\text { Boundary } \\
\text { Reynolds } \\
\text { number } \\
(5)\end{array}$ \\
\hline Corn & 5 & 1,970 & 1.17 & 0.615 & 795 \\
Corn & 13 & 1,660 & 1.38 & 0.726 & 868 \\
Corn & 29 & 1,220 & 1.77 & 0.931 & 986 \\
Corn & 61 & 948 & 1.97 & 1.04 & 1,040 \\
Corn & 84 & 862 & 1.88 & 0.99 & 1,010 \\
Cotton & 5 & 1,250 & 1.24 & 3.23 & 256 \\
Cotton & 28 & 876 & 1.59 & 4.15 & 290 \\
Cotton & 53 & 1,120 & 2.06 & 5.38 & 330 \\
Pine needles & 12 & 477 & 0.470 & 7.88 & 23 \\
Pine needles & 30 & 760 & 1.07 & 17.9 & 35 \\
Pine needles & 46 & 1,000 & 1.61 & 27.1 & 43 \\
Pine needles & 74 & 1,050 & 2.11 & 35.5 & 49 \\
Pine needles & 93 & 1,430 & 3.16 & 53.0 & 60 \\
Sorghum & 7 & 883 & 0.860 & 0.579 & 525 \\
Sorghum & 19 & 555 & 1.24 & 0.832 & 629 \\
Sorghum & 32 & 456 & 1.26 & 0.848 & 634 \\
Sorghum & 54 & 316 & 1.43 & 0.961 & 676 \\
Sorghum & 81 & 351 & 1.37 & 0.923 & 665 \\
Soybeans & 7 & 1,130 & 1.20 & 2.74 & 205 \\
Soybeans & 27 & 1,190 & 1.78 & 4.06 & 252 \\
Soybeans & 41 & 1,680 & 2.61 & 5.95 & 306 \\
Soybeans & 68 & 2,110 & 3.53 & 8.06 & 357 \\
Soybeans & 85 & 3,270 & 5.34 & 12.2 & 439 \\
Sunflower & 8 & 1,300 & 1.21 & 0.556 & 856 \\
Sunflower & 24 & 770 & 1.65 & 0.760 & 1,010 \\
Sunflower & 51 & 665 & 1.70 & 0.784 & 1,020 \\
Sunflower & 73 & 729 & 1.87 & 0.862 & 1,080 \\
Sunflower & 98 & 1,030 & 2.07 & 0.955 & 1,130 \\
Wheat & 8 & 244 & 0.535 & 2.24 & 66 \\
Wheat & 26 & 380 & 0.845 & 3.54 & 83 \\
Wheat & 44 & 736 & 1.55 & 6.47 & 112 \\
Wheat & 64 & 889 & 2.04 & 8.53 & 128 \\
Wheat & 91 & 1,160 & 2.87 & 12.0 & 152 \\
\hline \hline & & & & & \\
\hline
\end{tabular}

substantial differences in critical shear stress were found for similar rates of residue. This fact would seem to imply that experimental conditions may have been different between study locations.

Substantial differences in critical shear-stress values for both corn and wheat residue were found between results from the present investigation and those from the study reported by Foster et al. (1982a), particularly at the higher residue rates. The visually determined flow velocities reported by Foster et al. may have been larger than true averages. Flow may have been concentrated in row middles rather than spread in a broad sheet as assumed when calculating critical shear stress. In addition, differences in soil-surface roughness, residue orientation, and residue characteristics may have existed between the two investigations. 


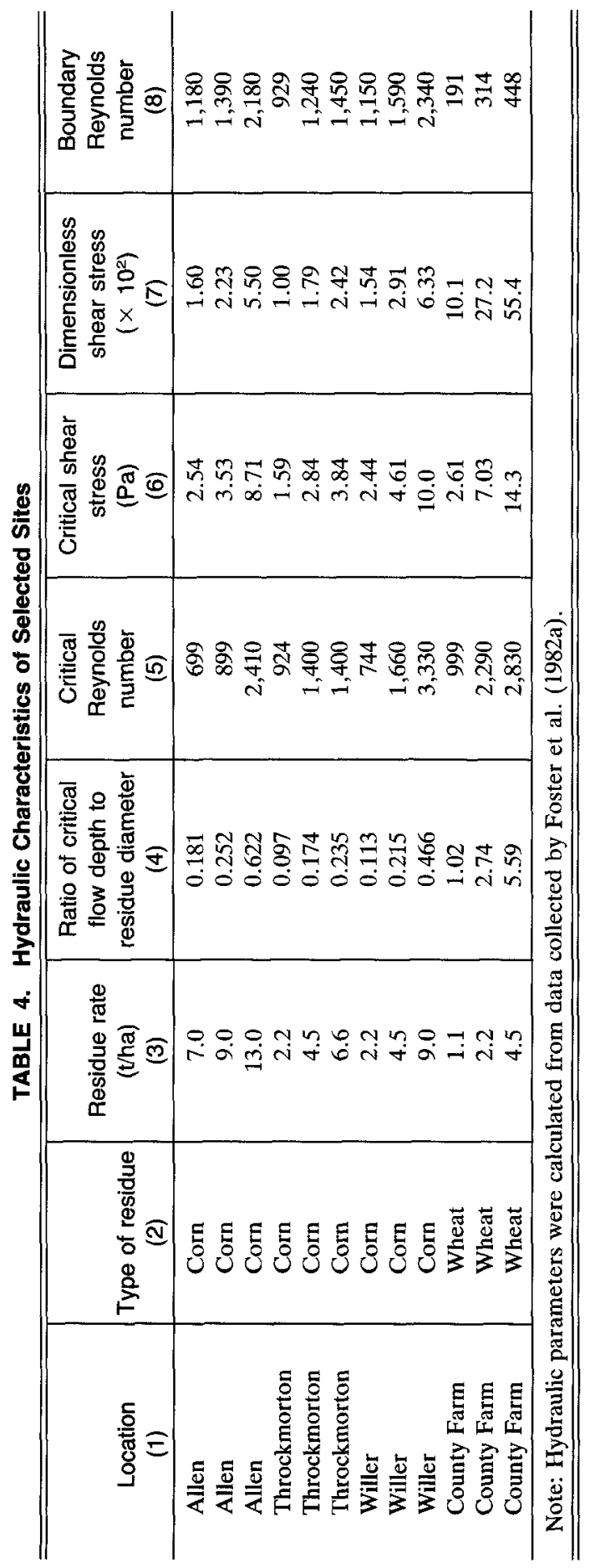




\section{Dimensionless Shear Stress and Boundary Reynolds Number}

Dimensionless shear stress and boundary Reynolds number values for each of the residue materials are shown in Table 3 and in Fig. 1. It can be seen from Table 3 that for a given residue material, dimensionless shear stress and boundary Reynolds number usually increase with surface cover. Dimensionless shear-stress values were greater for the smaller diameter materials. In contrast, greater boundary Reynolds number values were identified for the larger diameter residue materials.

Diameters of the residue materials used in the present study (Table 1) varied by two orders of magnitude. Since residue diameter is used explicitly in both the dimensionless shear stress and boundary Reynolds number equations, it is not surprising that values for both of these parameters varied by three orders of magnitude (Fig. 1). Differences in dimensionless shear stress caused by varying surface cover were much greater for the smaller diameter residue materials.

Dimensionless shear stress and boundary Reynolds number values for the sites examined by Foster et al. (1982a) are shown in Table 4. These two parameters were much larger than corresponding estimates obtained in the present investigation. Again, differences in flow characteristics, soil-surface roughness, residue orientation, or residue characteristics may have been present between the two studies.

\section{Estimating Dimensionless Shear Stress}

Fig. 1 shows that for a particular residue material, dimensionless shear stress and boundary Reynolds number may vary over a relatively large range, depending on the amount of surface cover. However, for each residue material, a single dimensionless shear-stress value can be found for each boundary Reynolds number. The following equations were derived to predict dimensionless shear stress:

$$
F^{*}=a\left(\mathrm{R}^{*}\right)^{2}
$$

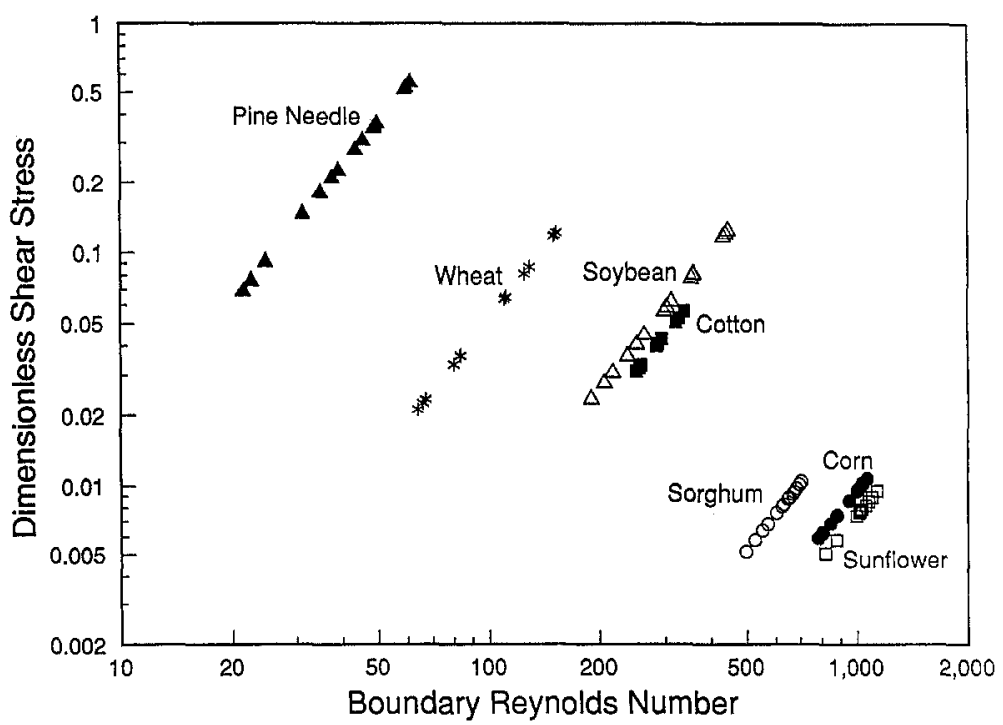

FIG. 1. Dimensionless Shear Stress versus Boundary Reynolds Number 
where

$$
a=\frac{1.25 \times 10^{-4}}{-0.482+D^{3}}
$$

and residue diameter $D$ is in mm. Since $a>0, D$ must be greater than 0.8 $\mathrm{mm}$. This relation can be used to predict parameter values for a wide variety of residue materials since $D$ is included explicitly in (13).

Values of the regression coefficient $a$ for residue materials with varying diameters are shown in Fig. 2. For the residue materials used in the present study, the regression coefficient $a$ varied by six orders of magnitude. Fig. 2 shows that actual values of the regression coefficient $a$ and estimates obtained using (13) generally agreed closely.

Dimensionless shear stress was calculated for each of the residue materials using (12) and (13). Results of the analyses are shown in Fig. 3. Predicted and actual values of dimensionless shear stress presented in Fig. 3 were similar.

Predicted and actual values of dimensionless shear stress were also compared using linear-regression analyses. Results of the statistical analyses are shown in Table 5. A coefficient of determination value of 0.962 was found for (12).

The hypotheses that the regression coefficient shown in Table 5 for the dimensionless shear-stress equation equals 1 and the intercept equals 0 were evaluated at the $95 \%$ confidence level using the Student's t-test. The slope was not significantly different from 1 nor the intercept significantly different from 0 . Thus, analyses of the experimental data suggest that (12) and (13) can be used to estimate dimensionless shear stress.

\section{Estimating Boundary Reynolds Number}

To use (12), the boundary Reynolds number must be known. The following equation was obtained to estimate the boundary Reynolds number

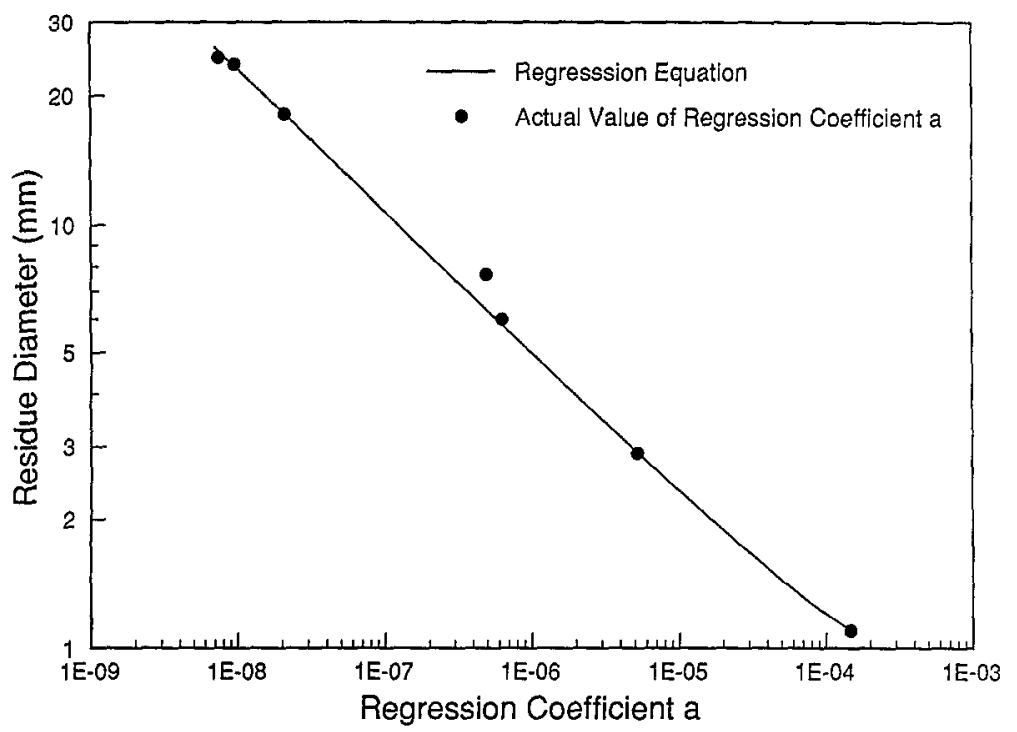

FIG. 2. Residue Diameter versus Regression Coefficient $a$ 


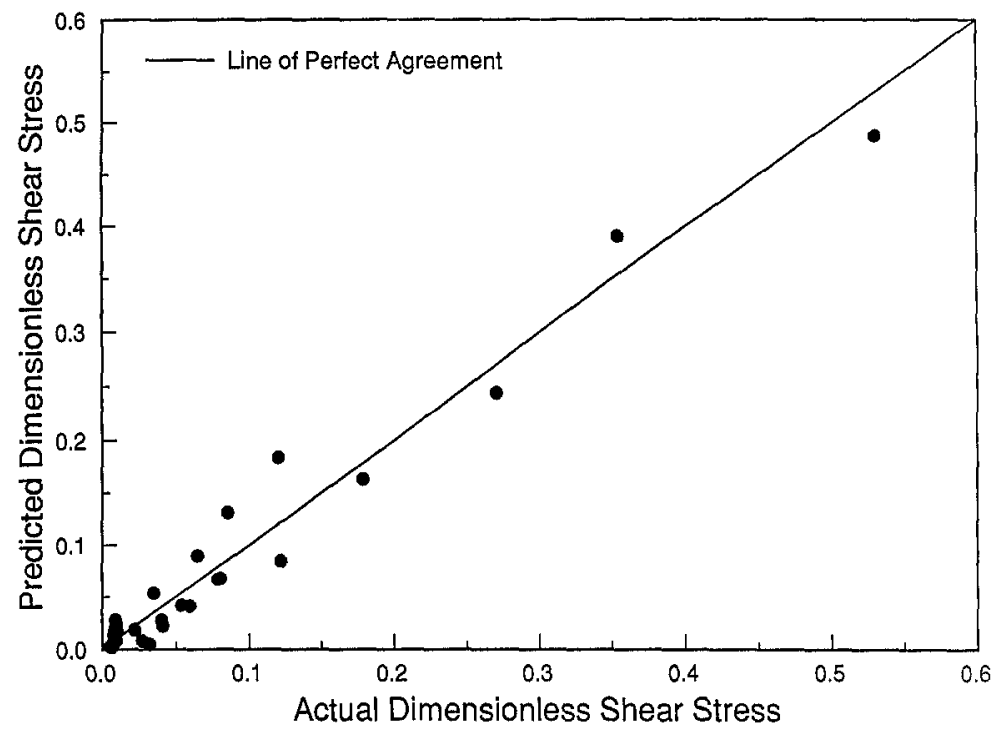

FIG. 3. Predicted versus Actual Dimensionless Shear Stress

TABLE 5. Predicted versus Actual Values of $F^{\star}$ and $\mathrm{R}^{\star}$ Obtained Using Regression Equations

\begin{tabular}{c|c|c|c|c|c|c}
\hline & & \multicolumn{2}{|c|}{$\beta_{1}$} & \multicolumn{2}{|c}{$\beta_{0}$} \\
\cline { 3 - 7 } $\begin{array}{c}\text { Regression equation } \\
(1)\end{array}$ & $\begin{array}{c}\text { Coefficient of } \\
\text { determination } \\
(2)\end{array}$ & $\begin{array}{c}F \\
(3)\end{array}$ & $\begin{array}{c}\text { Student's } \\
\mathrm{t} \\
(4)\end{array}$ & $\begin{array}{c}\text { Standard } \\
\text { error } \\
(5)\end{array}$ & $\begin{array}{c}\text { Student's } \\
\mathrm{t} \\
(6)\end{array}$ & $\begin{array}{c}\text { Standard } \\
\text { error } \\
(7)\end{array}$ \\
\hline $\begin{array}{c}F^{*} \text { (predicted }=0.961 \\
\text { actual + 0.003) }\end{array}$ & 0.962 & 777 & 1.15 & 0.034 & 0.590 & 0.005 \\
$\begin{array}{c}\mathrm{R}^{*} \text { (predicted =0.977 } \\
\text { actual + 11.3) }\end{array}$ & 0.977 & 1,310 & 0.858 & 0.027 & 0.680 & 16.6 \\
\hline
\end{tabular}

$$
\mathrm{R}^{*}=11.26+33.56(D)+0.1220(D \times \text { cover })
$$

where $D$ is in $\mathrm{mm}$, and cover is given as a percentage. Since residue diameter and surface cover are included explicitly in this relationship, it can be used to estimate the boundary Reynolds number for residue materials not included in the present study.

Eq. (14) was used to calculate boundary Reynolds number values for each of the residue materials. Results of the analyses are shown in Fig. 4, which shows that predicted and actual boundary Reynolds number values were similar.

Linear-regression analyses were used to compare predicted and actual boundary Reynolds number values. Results of the statistical analyses are shown in Table 5. A coefficient of determination value of 0.977 was found for (14).

The Student's t-test was used to evaluate the hypotheses that the regression coefficient shown in Table 5 for the boundary Reynolds number equation equals 1 and that the intercept equals 0 at the $95 \%$ confidence level. The slope was not significantly different from 1 nor was the intercept sig- 


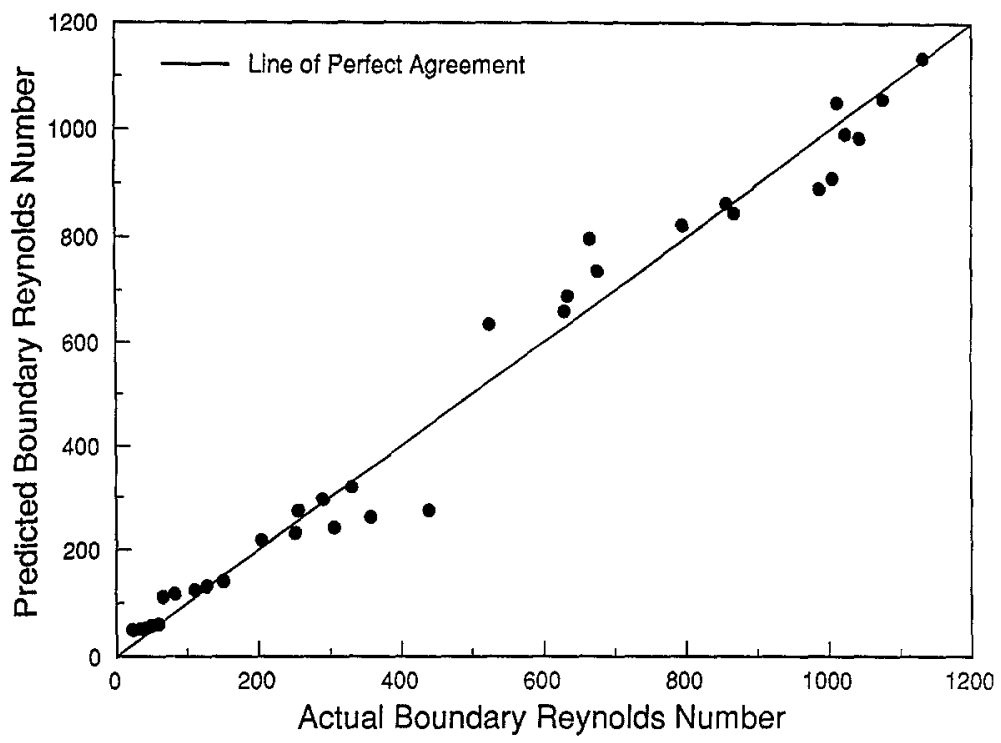

FIG. 4. Predicted versus Actual Boundary Reynolds Number

nificantly different from 0 . Thus, analyses of the experimental data suggest that (14) can be used to estimate the boundary Reynolds number.

\section{Limitations of Regression Equations}

In the present investigation, only unanchored residue materials were used. A residue element may be partially buried following tillage. Other residue elements may be wedged between plants still anchored within the soil or between gravel and cobble materials. Movement of partially anchored residue elements requires much larger shear stresses.

Straw is sometimes added to irrigation furrows to reduce erosion. If the added residue is to be effective, it must remain in place. To minimize movement of straw by irrigation flow, it may be necessary to incorporate the residue material into the soil.

Crop residue within irrigation furrows frequently causes greater infiltration rates and decreased irrigation uniformity. Surge irrigation has been shown to reduce infiltration, increase advance rate, and improve irrigation efficiencies. Thus, surge-irrigation systems are especially well suited for use on areas containing substantial residue cover.

Lane (1953) reported the effects of grain diameter on critical shear stress for noncohesive materials. Shear-stress values less than those required to initiate residue movement may be large enough to allow detachment and transport of some sand-sized material. The detached soil may settle in small ponds created by individual residue elements, providing increased stability to residue materials. Under these conditions, critical shear-stress values much larger than those reported in Table 3 would be required to cause residue movement.

\section{SUMMARY AND CONCLUSIONS}

Significant soil loss may occur on some furrow irrigated areas. Relatively small amounts of crop residue can substantially reduce erosion within fur- 
rows. Conservation tillage systems are designed to maintain crop residue from previous crops on the soil surface. Straw can also be added to furrows using specially designed farm equipment. However, if crop residues are to be effective in reducing soil loss, they must not be removed by irrigation flow.

In the present study, selected amounts of corn, cotton, pine needles, sorghum, soybean, sunflower, and wheat residue were used. The residue materials were placed in a flume on a sand surface, and flow was then introduced in progressive increments. The discharge rate and flow velocity required to initiate residue movement were identified.

Hydraulic measurements were used to calculate the ratio of critical flow depth to residue diameter, critical Reynolds number, critical shear stress, dimensionless shear stress, and boundary Reynolds number. Regression equations were then developed to relate dimensionless shear stress to the boundary Reynolds number, and to estimate the boundary Reynolds number from values of residue diameter and cover. Since residue diameter and cover are included explicitly in the regression equations, they can be used to estimate hydraulic conditions required to move other residue materials.

The accuracy of the regression equations for estimating dimensionless shear stress and the boundary Reynolds number was evaluated. Close agreement was found between predicted and actual values. Thus, the regression equations appear to provide reliable estimates of the hydraulic conditions required to move unanchored residue materials.

Either buoyancy or drag forces can serve to move crop residue resting on the soil surface. Buoyancy forces appear to significantly influence incipient motion for larger diameter crop residue such as corn, sorghum, or sunflower. In contrast, smaller diameter residue materials such as cotton, pine needles, soybean, and wheat appear to be moved primarily by drag forces.

Both buoyancy and drag forces depend on the same hydraulic variables. Thus, standard procedures used to identify incipient motion usually incorporate both buoyancy and drag forces in the analyses. In the present study, analytical procedures are derived for estimating incipient residue movement.

Information on residue spacing and the ratio of residue spacing to residue diameter provide insight into the flow processes affecting residue movement. Isolated-roughness flow (Chow 1959) appears to be the predominate flow condition at the lower residue rates. For intermediate residue rates, wakeinterference flow appears to occur. Quasi-smooth flow appears to dominate at the higher residue rates.

Critical shear stress is defined as the force per unit area required to initiate movement of the residue material. As residue materials overlap at higher residue rates, increased stability appears to occur. As a result, critical shearstress values were found to consistently increase with surface cover for each of the residue materials.

Analytical procedures developed by Shields (Simons and Senturk 1976) have been used extensively to estimate the beginning of motion for noncohesive particles. In the present study, selected equations presented by Shields were adapted for use with unanchored residue materials. It appears that the analytical procedures derived by Shields can also be used to estimate incipient motion for residue materials. 


\section{ACKNOWLEDGMENT}

This paper is a contribution from the U.S. Dept. of Agriculture-Agricultural Research Service, Lincoln, Neb., in cooperation with the Agricultural Research Division, University of Nebraska, also in Lincoln, and is published as journal series number 10390 .

\section{APPENDIX I. REFERENCES}

Aarstad, J. S., and Miller, D. E. (1978). "Corn residue management to reduce erosion in irrigation furrows." J. Soil and Water Cons., 33(6), 289-291.

Aarstad, J. S., and Miller, D. E. (1981). "Effect of small amounts of residue on furrow erosion." Soil Sci. Soc. Am. J., 45(1), 116-118.

Brown, M. J. (1985). "Effects of grain straw and furrow irrigation stream size on soil erosion and infiltration." J. Soil and Water Cons., 40(4), 389-391.

Brown, M. J., and Kemper, W. D. (1987). "Using straw in steep furrows to reduce soil erosion and increase dry bean yields." J. Soil and Water Cons., 42(3), 187191.

Chow, V. T. (1959). Open Channel Hydraulics, McGraw Hill, Inc., New York, N.Y.

Deason, J. P. (1989). "Irrigation-induced contamination: how real a problem?" $J$. Irrig. and Drain. Engrg., ASCE, 115(1), 9-20.

Foster, G. R., Johnson, C. B., and Moldenhauer, W. C. (1982a). "Critical slope lengths for unanchored cornstalk and wheat straw residue." Trans., Am. Soc. Agric. Engrs., 25(4), 935-939, 947.

Foster, G. R., Johnson, C. B., and Moldenhauer, W. C. (1982b). "Hydraulics of failure of unanchored cornstalk and wheat straw mulches for erosion control." Trans., Am. Soc. Agric. Engrs., 25(4), 940-947.

Gilley, J. E., and Finkner, S. C. (1991). "Hydraulic roughness coefficients as affected by random roughness." Trans., Am. Soc. Agric. Engrs., 34(3), 897-903.

Gilley, J. E., and Kottwitz, E. R. (1992). "Beginning of motion for selected unanchored residue materials." J. Irrig. and Drain. Engrg., ASCE, 118(4), 619-630.

Gilley, J. E., Kottwitz, E. R., and Simanton, J. R. (1990). "Hydraulic characteristics of rills." Trans., Am. Soc. Agric. Engrs., 33(6), 1900-1906.

Gilley, J. E., Kottwitz, E. R., and Wieman, G. A. (1991). "Roughness coefficients for selected residue materials." J. Irrig. and Drain. Engrg., ASCE, 117(4), 503514.

Gilley, J. E., Kottwitz, E. R., and Wieman, G. A. (1992). "Darcy-Weisbach roughness coefficients for gravel and cobble surfaces." J. Irrig. and Drain. Engrg., ASCE, 118(1), 104-112.

Laflen, J. M., Baker, J. L., Hartwig, R. O., Buchele, W. F., and Johnson, H. P. (1978). "Soil and water loss from conservation tillage systems." Trans., Am. Soc. Agric. Engrs., 21(5), 881-885.

Lane, E. W. (1953). "Design of stable channels." ASCE Trans., Am. Soc. Civ. Engrs., 120, 1234-1260.

Miller, D. E., and Aarstad, J. S. (1983). "Residue management to reduce furrow erosion." J. Soil and Water Cons., 38(4), 366-370.

Miller, D. E., Aarstad, J. S., and Evans, R. G. (1987). "Control of furrow erosion with crop residues and surge flow irrigation." Soil Sci. Soc. Am. J., 51(2), 421425 .

Shen, H. W., and Li, R. M. (1973). "Rainfall effect on sheet flow over smooth surface." J. Hydr. Div., ASCE, 99(5), 771-792.

Simons, D. B., and Senturk, F. (1976). Sediment Transport Technology, Water Resources Publications, Fort Collins, Colo.

\section{APPENDIX II. NOTATION}

The following symbols are used in this paper: 


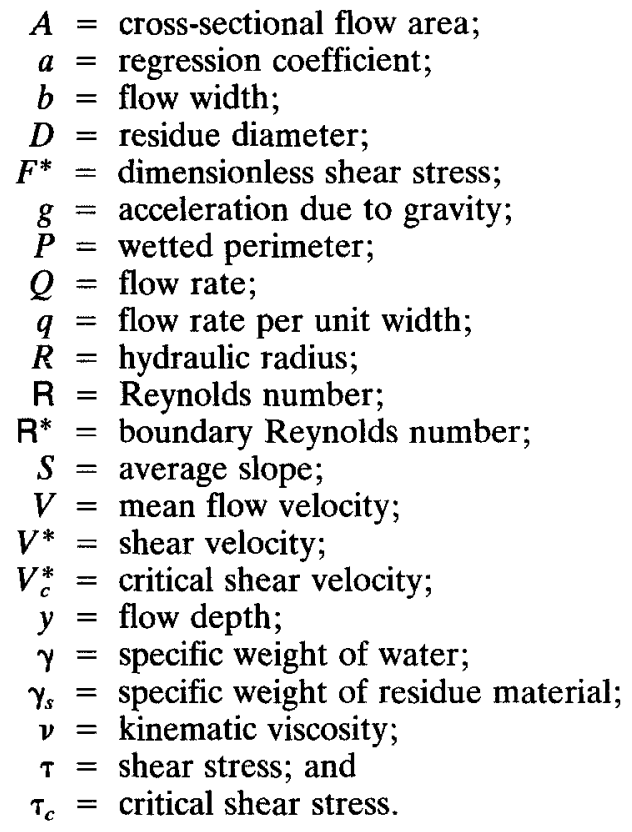

